\title{
Exploration of the effect of the COVID-19 outbreak on women's access to family planning services in Port Said and Souhag governorates [Arabic]
}

Evidence Project

Follow this and additional works at: https://knowledgecommons.popcouncil.org/departments_sbsr-rh How does access to this work benefit you? Let us know!

\section{Recommended Citation}

Evidence Project. 2021. "Exploration of the effect of the COVID-19 outbreak on women's access to family planning services in Port Said and Souhag governorates [Arabic]." Cairo: Population Council, The Evidence Project. 


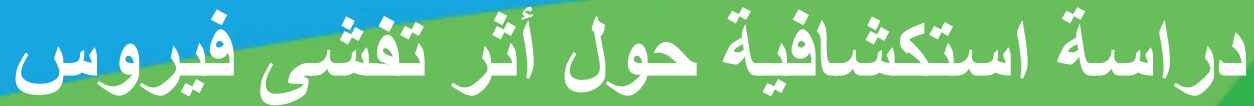

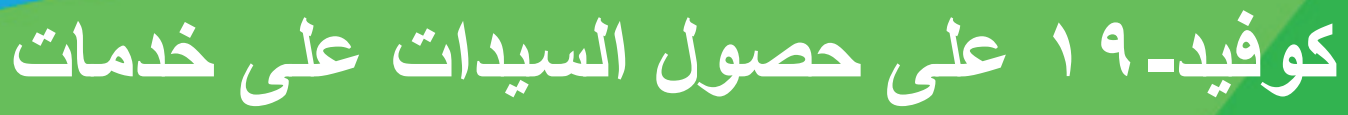

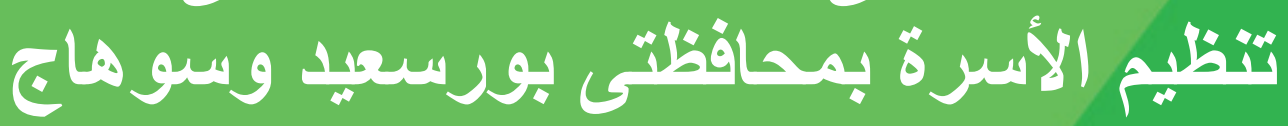

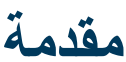

التجارية والترفيهية، وتم التحول للعمل من المنزل

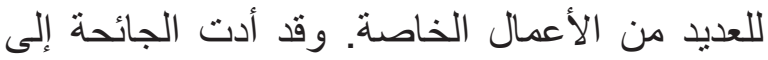

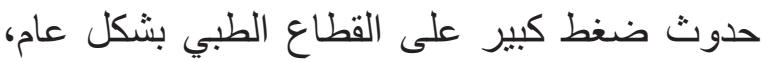
مما أدى إلى توجيه الموارد الطبية المختلفة لعلاج الحالات المصابة والحد من إنتشار الفيروس.

وتثير الخبرات الدولية إلى أن حصول السيدات على خدمات تتظيم الأسرة والصحة الإنجابية قد الن يتأثر بشكل ملحوظ نتيجة لتفشي فيروس كوفيد-9 19

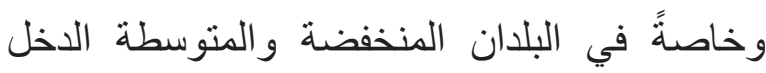
بسبب الاعباء المالية لاى بعض الأسر وصعوبة الوصول الى مقدمي الخدمة وتحويل بعض الطو الطواء اقد الطبية للعلاج. كما أن الجائحة قد أدت إلى تلى تعطيل

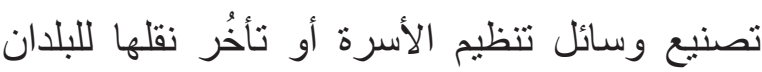
النامية نتيجة لإجر اءات الحظر (UNFPA, 2020). وتثير التقديرات الدولية إلى أن حوالي rامليون

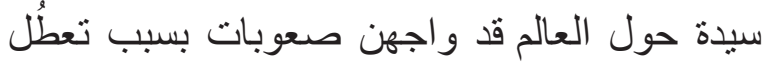
خدمات تنظيم الأسرة والصحة الإنجابية خلال عالمي

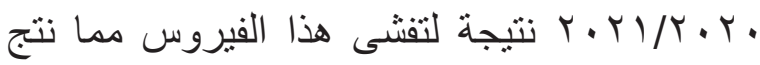
عنه حدوث حولي ع , ا مليون حالة حمل غير مخطط له

وبالنسبة للوضع فى مصر فتشير بعض التقارير إلى اللى انخفاض الطلب على خدمات تنظيم الأسرة والصحة الإنجابية اثناء الموجة الأولى لتفنى كوفيد-19 فى النى
كوفيد-19 هو مرض يصيب الجهاز التنفسى يسببه فيروس كورونا المستجد الذي تم اكتثافه

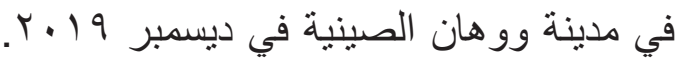
وقد تحوّل مرض كوفيد-19 إلى جائحة تؤُثر على العديد من بلدان العالم وطلى طيلى طبيعة

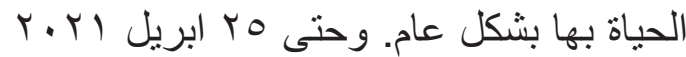
تم تسجيل حوالى و و طبقا لإحصائيات منظمة الصحة العالمية .(World Health Organization, 2021) وفي مصر نم الإعلان عن أول حالة إصابة

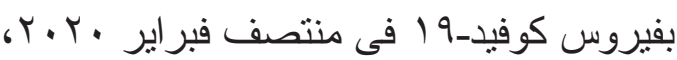
وبعدها بدأت حالات الإصابة فى إزدياد. وقد فئر

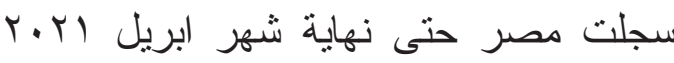
ع ع Pr, OV.

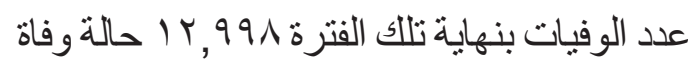
.(World Health Organization, 2021) وكما هو الحال فى معظم بلدان العالم، تأترت الحباة العامة في مصر بثكل واضح في حيثل تم إنخاذ إجراءات إحترازية مشددة للحد من العن إنتشار الفيروس داخل البلاد فى الموجة الأولى الفي

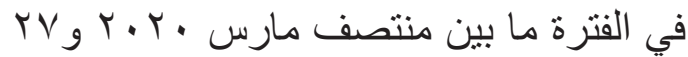

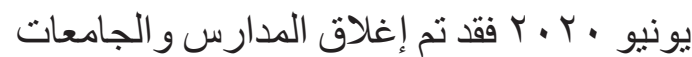

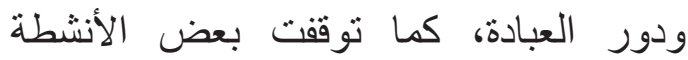


تم جمع البيانات الخاصة بهذه الدراسة خلال الفترة

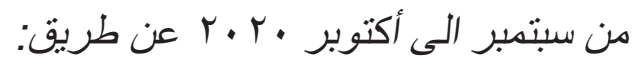

1. مقابلات هاتفية مع عينة مكونة من . . ب طبيب

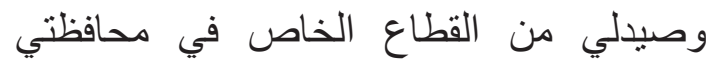

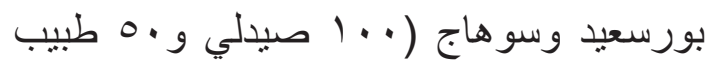

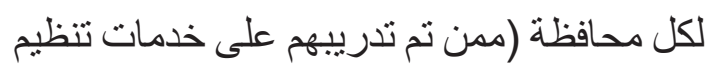
الأسرة والصحة الإنجابية من خلال المشروع. r. مقابلات هاتفية متعققة مع عينة من ·r سيدة

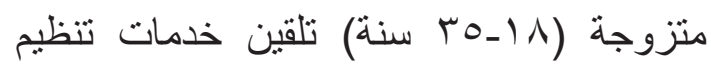

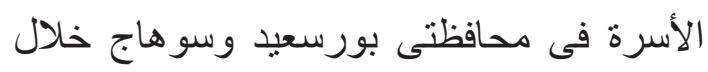

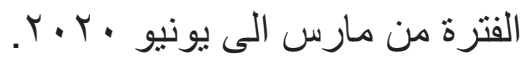

\section{أهم النتائج}

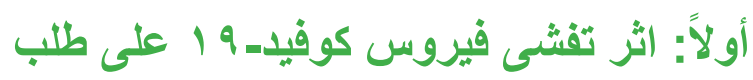

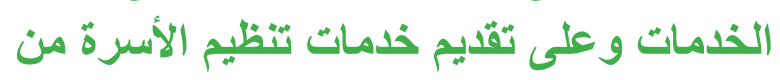
وجهة نظر الأطباء و الصيادئة

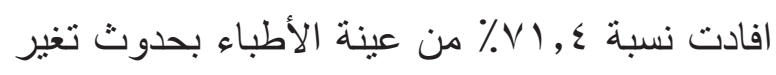

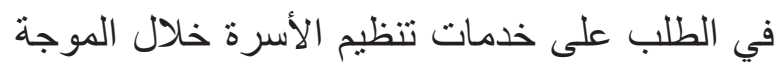

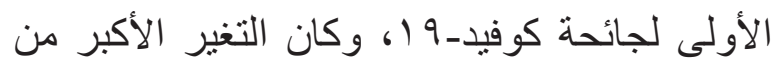

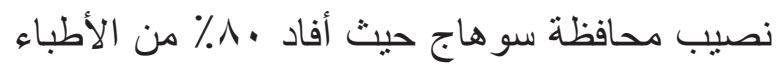

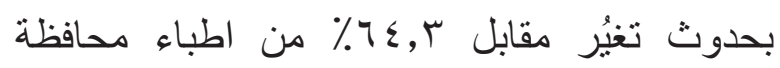

$$
\text { بورسعيد. }
$$

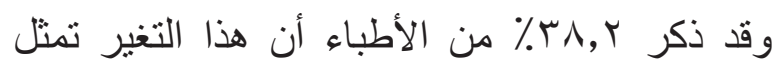

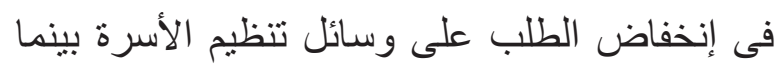

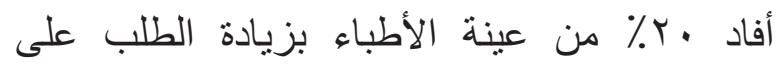

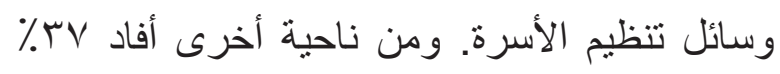

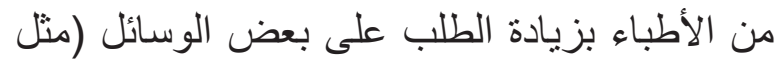

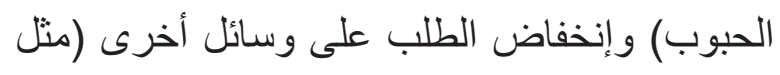

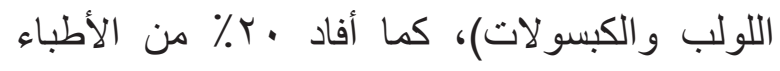

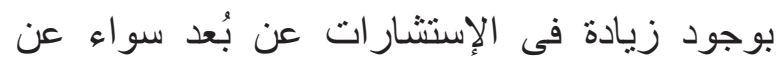
طريق التلبفون أو الو اتس أب (شكل رقم النئ ().

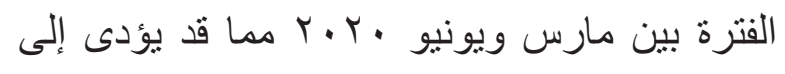
إنخفاض معدلات إستخدام وسائل تنظيم الأسرة

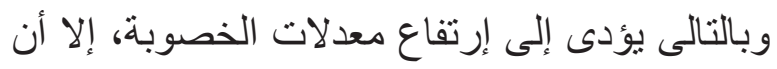

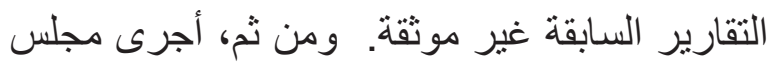

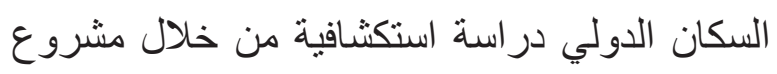

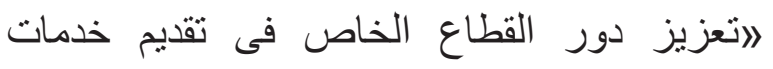

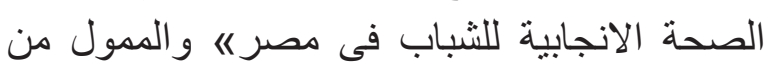

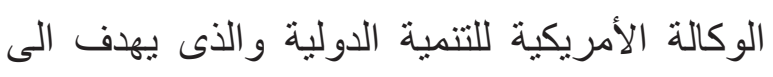

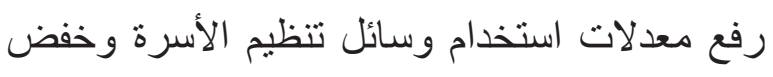

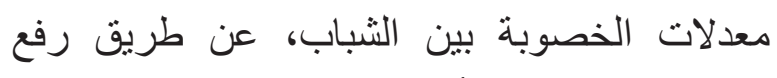

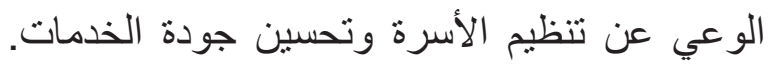

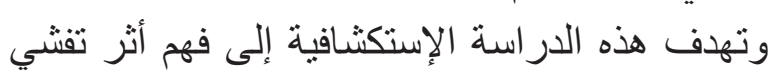

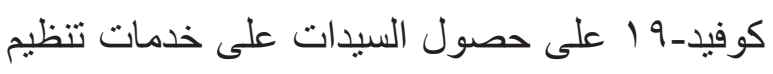

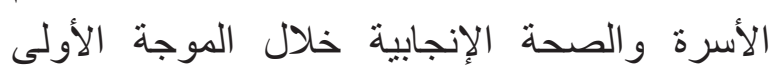

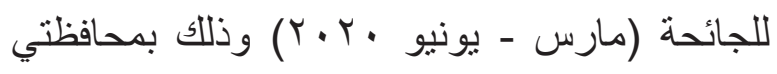

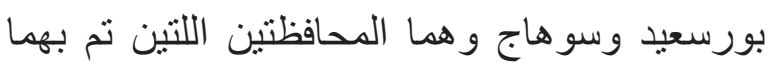

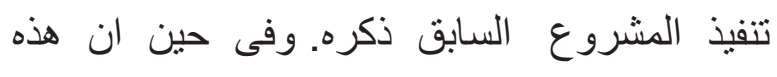

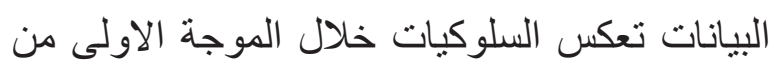

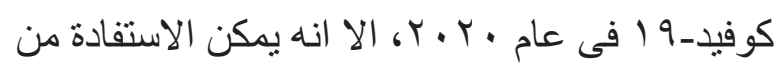

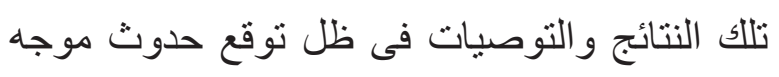
رابعة للوباء وحدوث تتطور بالفيروس.

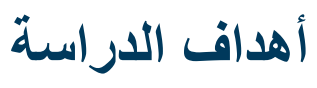

$$
\text { تمثلت اهداف الدراسة فيما يليى: }
$$

1. التعرف على التغيرات التى طر أت على الطلب

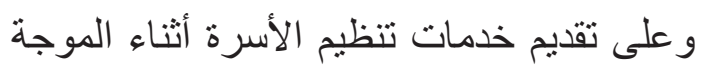

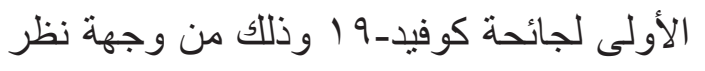
الأطباء و الصيادلة.

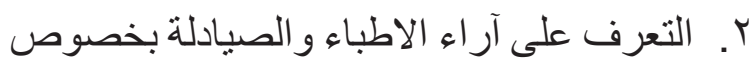

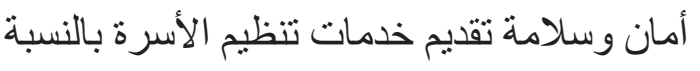
للمنتفعات ومقدمي الخدمة خلال الموجة الأولى بلى بلى

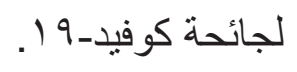

r. التعرف على التحديات التى واجهت السيدات فى تلى

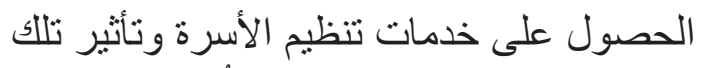
التحديات على هؤ لاء السيدات و أُسر هن. 
الأولى لجائحة كوفيد-9 1، وكان هناك تباين بسيط

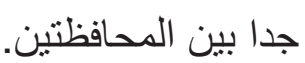

و إذا تطرقنا إلى نوع التغير الذي طر أ على الخدمة

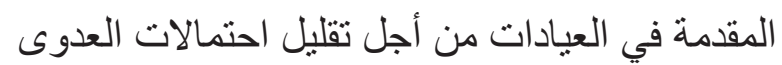

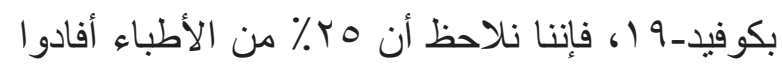
بأنهم أغلقوا عياداتهم الخاصة لفترة ثم أعادوا فتحها

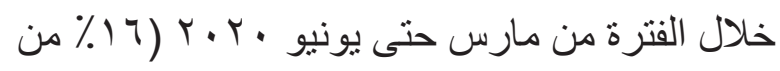

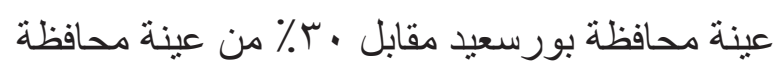

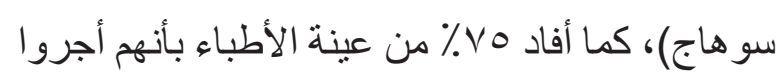
تعديلات فى مواعيد العمل بعياداتهم الخاصة نتيجة

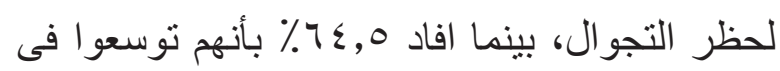

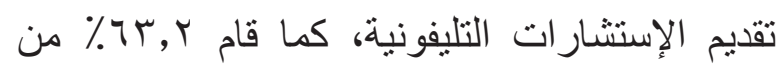
الأطباء بخفض عدد الحالات التي بتم استقبالها.
أما بالنسبة للصيادلة، فقد ذكر ه, 1 \% من الصيادلة أنه

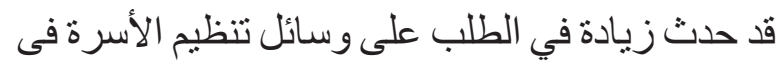

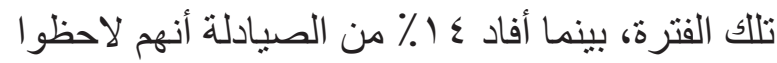

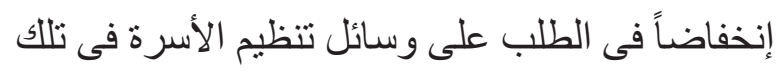

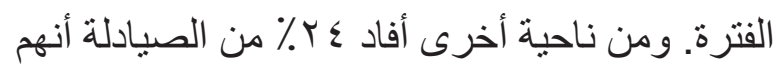
لآحظوا زيادة فى الطلب على بعض الوسائل (مثل

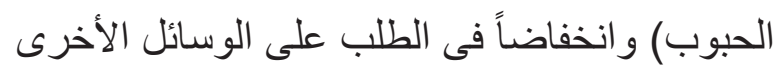

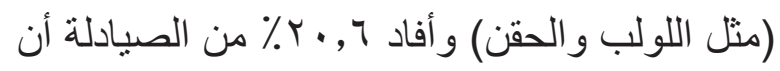

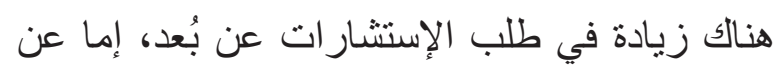

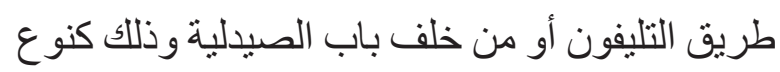
من أنواع الوقاية من العدوى.

ومن ناحية تقديم الخدمة، أفادت الأغلبية العظمى من

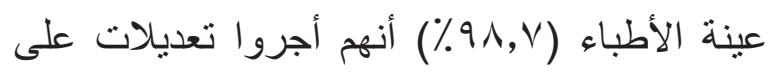
الخدمة المقدمة في عياداتهم الخاصة أثناء الموجة أعرداء

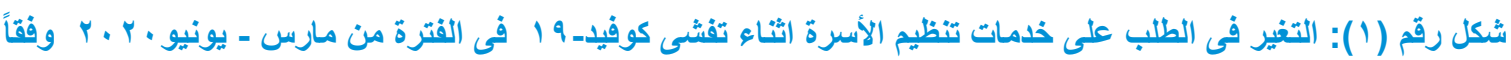
لآراء الأطباء و الصيادلة $\% 1$.

$\% \wedge$.

$\%$

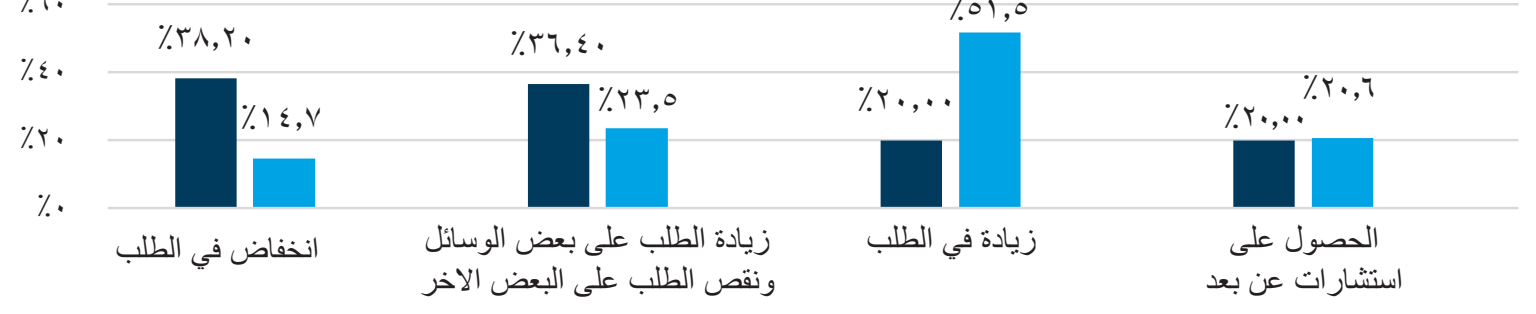

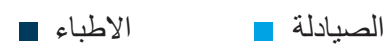

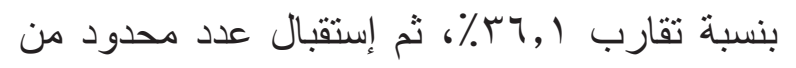

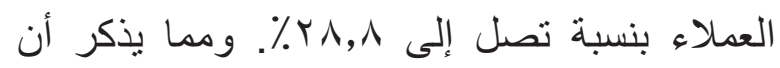

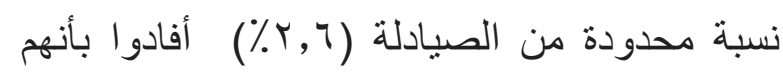

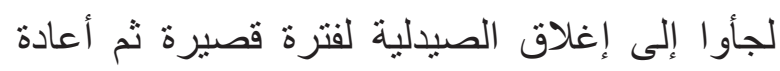
فتحها (شكل رقم r).
أما إذا تطرقنا للتغير الذى طر أ على تقديم الخدمة

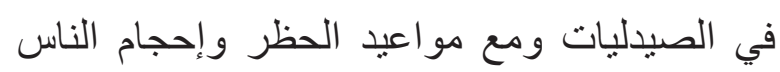

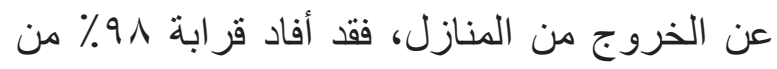

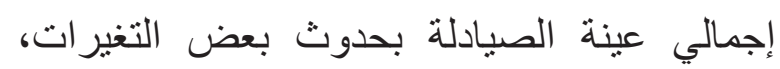

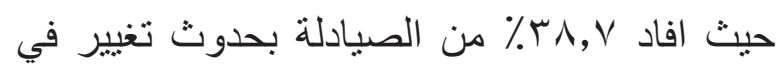
مو اعبد الصيدلية، يلي ذلك تقديم إستشار ات تلبفونية 


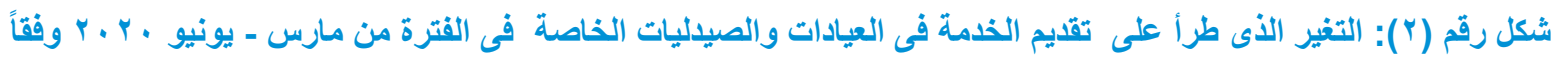
لآراء الأطباء والصيادلة (سُمح بتعدد الاجابات) $\% 1$.

$\%$.

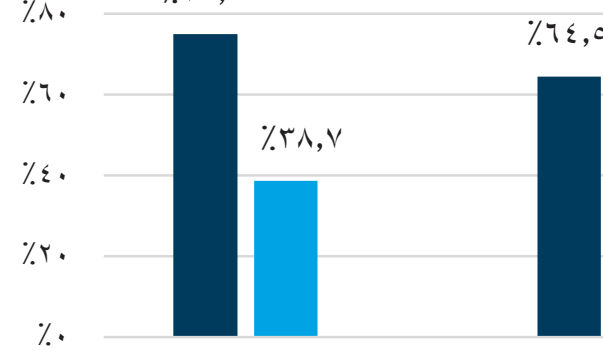
$\%$ १, 0 $\% \pi r, r$ تغيير مواعبد العمل

تقليل عدد الحالات فى المنشأة زيادة الإستثار ات التليفونية

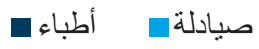

الأطباء عن الوسائل غير الأمنة أفادوا بأن اللولب

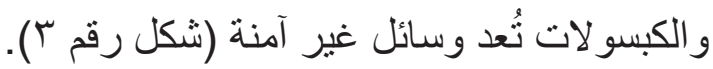

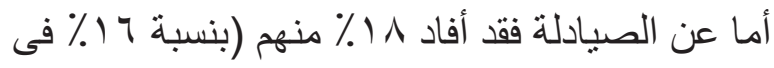

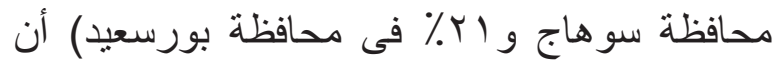

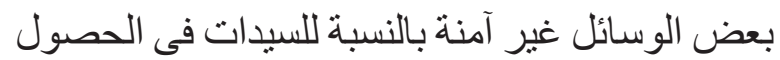

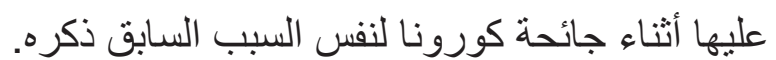
و عن الوسائل غير الآمنة ذكر هؤلاء الصيادلة الحقن بالإضافة للولب و الكبسو لات.
ثنانياً: وجهات نظر الأطباء والصيادلة حول امان وسلامة تقديم خدمات تنظيم الأسرة بالنسبة للمنتفعات ومقدمي الخدمة أثناء

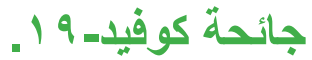
أوضحت الدر اسة أن · 1\% من إجمالى الأطباء (r\% فى محافظة سوهاج و^ (\% فى محافظة بورسعيد) يعتقدون أن بعض الوسائل غير آمنة للسيدات في

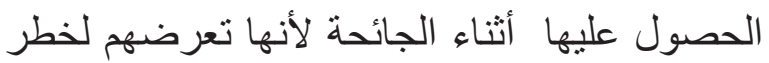
العدوى بالفيروس أثناء التركيب. وبسؤال هؤلاء

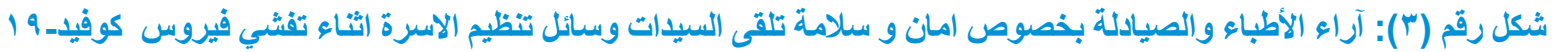
$\% 1$.

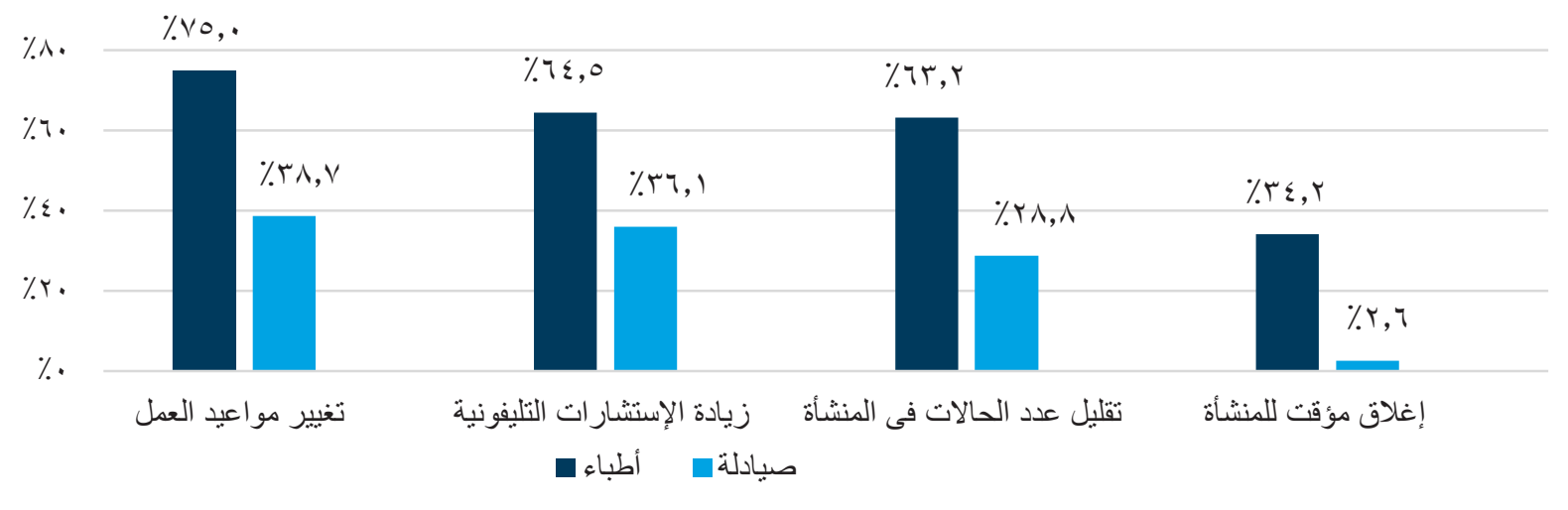


أما من ناحية امان و سلامة تقديم خدمات تنظيم الأسرة وبالمثل فقد أفاد بr\% من إجمالى عينة الصيادلة

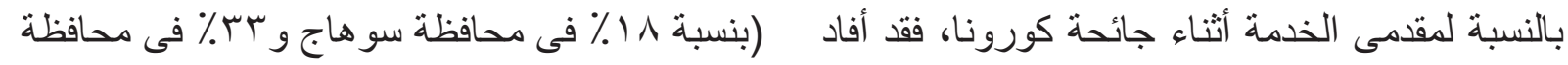

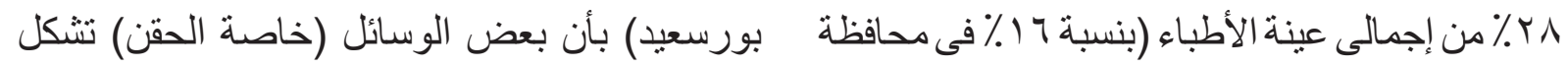

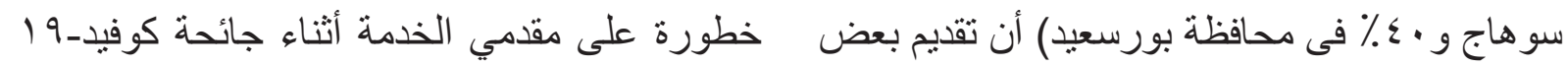

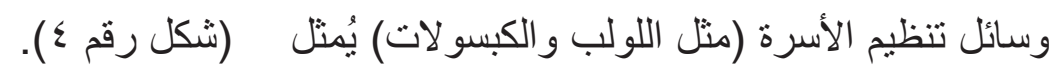

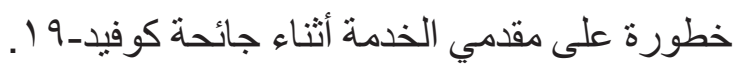

شكل رقم (؛ ): آراء الأطباء والصيادلة بخصوص امان و سلامة تقديم خدمات تنظيم الاسرة أثثاء تفشي فيروس كوفيد-19 $\%$..

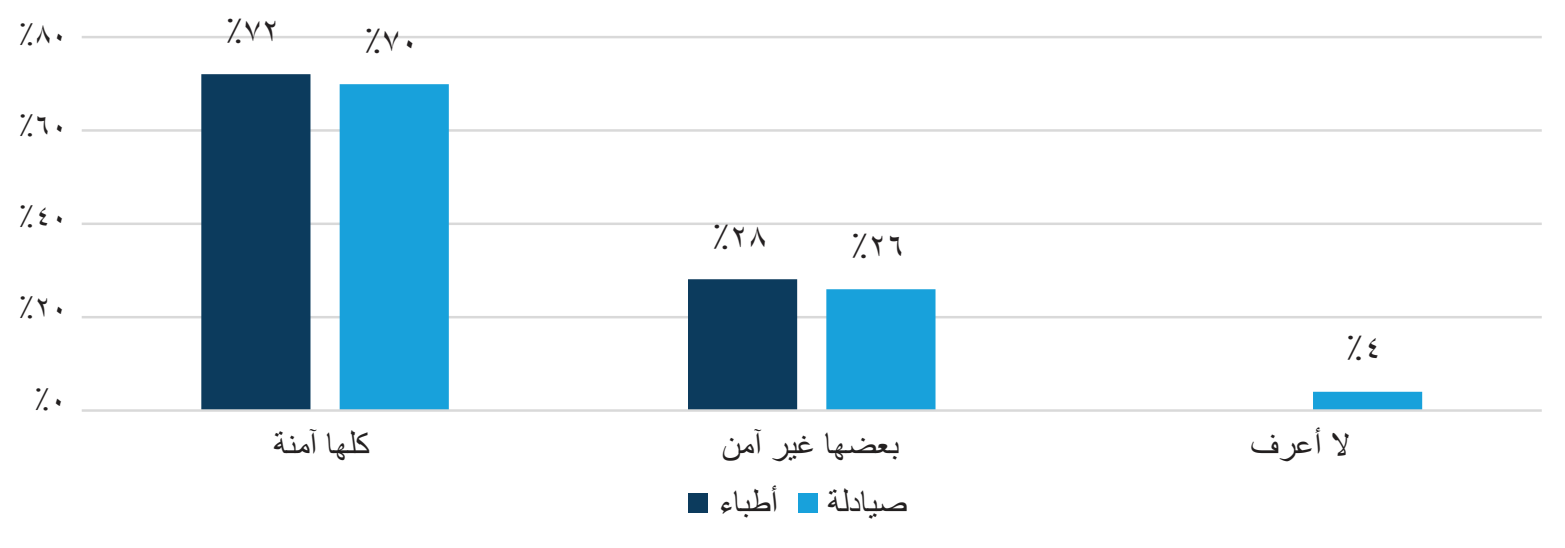

أما بالنسبة للصيادلة فقد أفاد V7\% منهم ان معظم

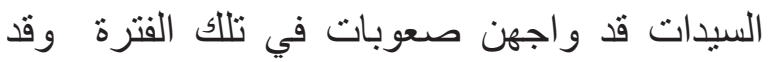
كانت النسبة ا^^٪ بين الصيادلة فى محافظة سو هاج

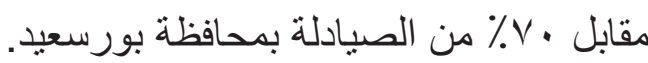

وكان من ابرز تللك الصعوبات و التحديات التىى

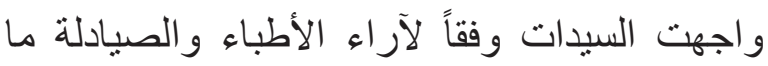
يلي : الخوف من العدوى (YV\%) - ساعات حظر

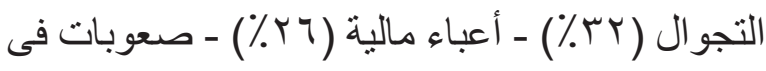
الحصول على بعض وسائل تنظيم الاسرة (7 (1\%)'.

وجهات نظر السبد/ت

وبسؤال السيدات عما إذا كُن قد واجهن صعوبات

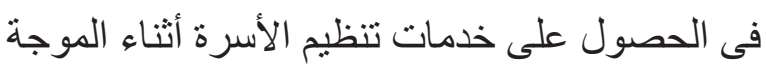

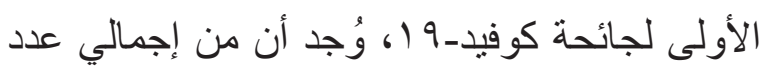

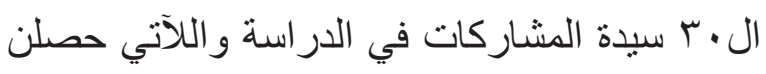

ثالثاً: التحديات التى واجهت السيدات فى

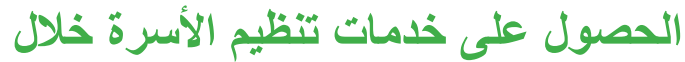

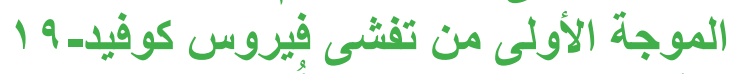
وتأثير ها على السيدات وأسر هم.

\section{وجهات نظر الأطباء والصيادلة}

بسؤ ال الأطباء و الصبادلة عما إذا كانو ا يعتقدون أن السيدات فى محافظتي سو هاج وبورسعيد قد واجهن صعوبات فى الحصول على خدمات تنظيم الأسرة والصحة الإنجابية أثناء الموجة الأولى من جائحة

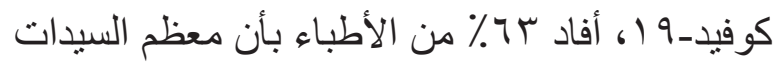
قد واجهن صعوبات فى تللك المرحلة. ولقد كان هناك الك تبايناً كبيراً بين المحافظتين، حيث بلغت نسبة الأطباء

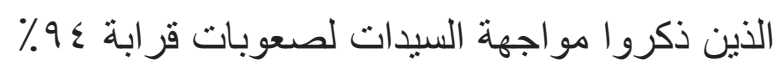

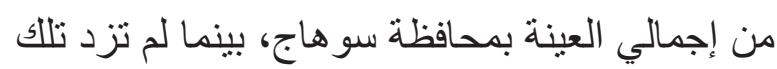

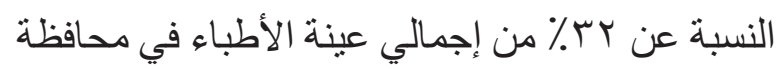


الأولى لجائحة كوفيد-19 (V ا سيدة) فقد تمثلت تللك

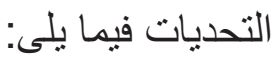

\section{• الخوف من انتقال عدوى كوفيد-9 1 :}

أفاد معظم السيدات بخوفهن من الخروج من المنزل

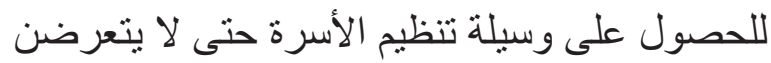

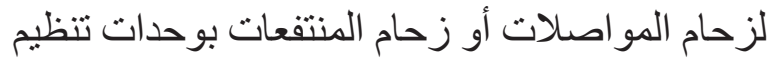
الأسرة، وخاصة ان بعض السيدات زليدات ذهبن أثناء فترة الحمل للحصول على تطعيم التيتانوس وفوجئن التصن بوجود زحام أثناء جلسات تطعيم الاطفال فخفن من النيان تكرار التجربة للحصول على الوسيلة.

وقد أدى خوف السيدات من الزحام في القطاع

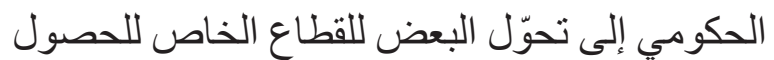

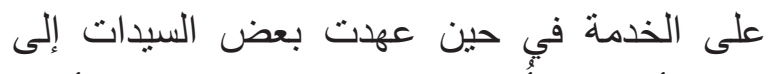
بعض أفراد الأسرة لإحضار وسيلة تنظيم الأسرة

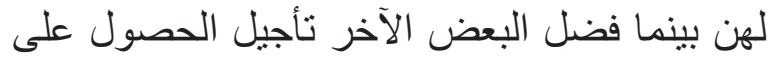
الخدمة لحين تحسن الظروف الصحية في البلاد. ومن أقو ال السيدات في هذا الثأن ما يلي:

الصر احة المرة دى غبرت بسبب الكورونا .. قبل كده

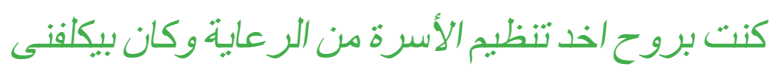

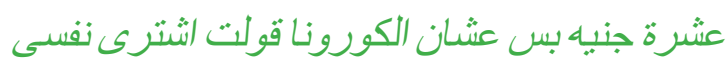

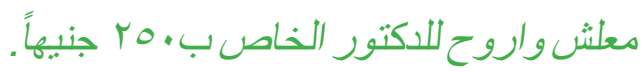

سيدة من محافظة سو هاج - ع ؟نة ولديها خمسة أطفال

\section{- 66}

\section{9}

يعنى مفيش غبير الخوف من انتشار العدوى وانى لدي

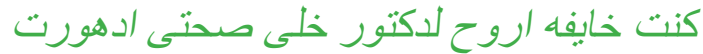

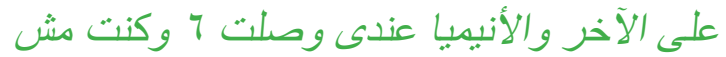

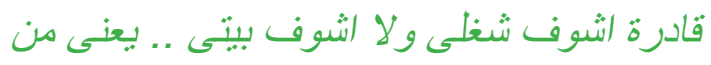

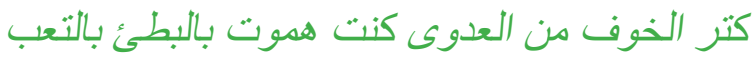

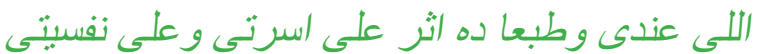

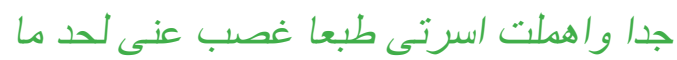
قدرت اتغلب على خوفى ورحت للاكتور.

سيدة من محافظة بورسعيد - عس سنة ولايها ثلاثة أطفال
على خدمات تنظيم الأسرة خلال الموجة الأولى

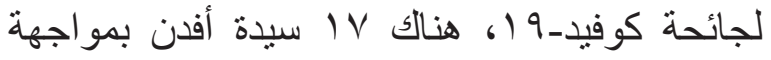
بعض التحديات، أما باقى السيدات (بات آسيدة) فأفدن

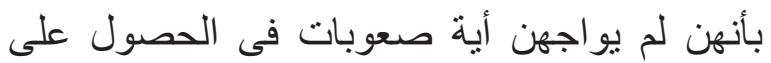
خدمات تنظيم الأسرة سواء من القطاع الحكومى أو أو القو

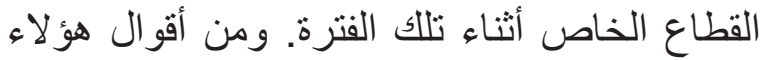

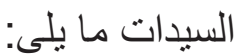

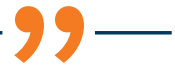

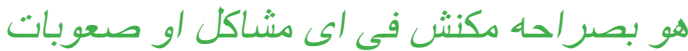
قابلتنى في الحصول على الوسيله بالعكس انا روحت المركز الصحى ودخلت على طول . .. اختارت الوسيله ومشيت ومكنش في ایى مشكله غير

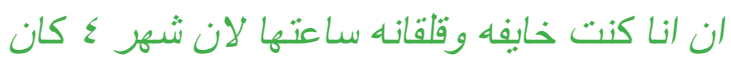
في عز ذروة كورونا والاعداد كانت كل يوم عماله تزيد فانا كنت بصر احه خايفه ان الدكان يكون

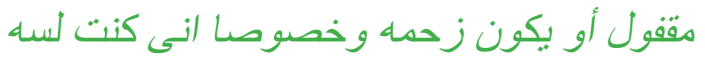

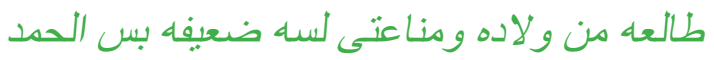
لله روحت لقيث المكان نظيف ومفيش زحمده وفي

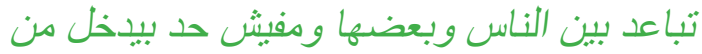
غير كمامه وكده فده اللى ريحنى شويه ل.... سيدة من محافظة بورسعيد - ع سنة ولديها ثلاثة أطفال

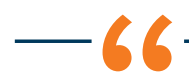

والله الدكتورة قالت لي بر احتلك عايزة تركبي لولب ماثي عايزة تاخدي برشام ماشى ... لو عارفة لونة نفسك هاتمشي على البرشام صح وتهتئمي وتاخدية في ميعاده مضبوط خدية لكن لو هاتنسي البرشام وأنتي مش عايزة حمل تاني دلوقتي ييقى ركبي لوني

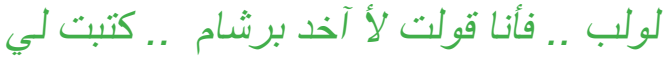

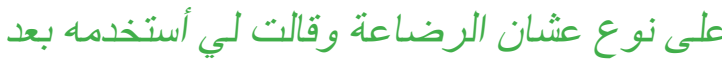
الأربعين هو متوفر على طول في الصبيلية وسعره عشرة جنية ونص والصيدلية قريبة من البيت. سبدة من حضر محافظة سوهاج - r سنة ولديها طفلان 66

أما بالنسبة للسيدات اللاتى واجهن صعوبات فى الكى الحصول على خدمات نتظيم الأسرة أثناء الموجة 
رحت الوحدة الصحية علثان مفهاث مصاريف كتبر وقريبه من بيتى وحالتى الماديه كمان على قدها

قالتللي الدكتورة مفيش تركيب لولب دلوقتى بس انسان

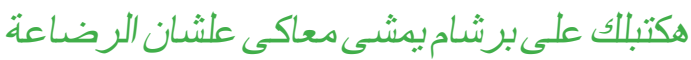

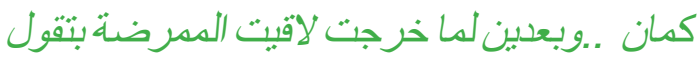
ان الدكتورة رفضة تركب لولب لحد علثان الكورونا خفت بصر /حة لما الدكتورة قالت كده وقولت لما تمشى لريى كورونا خالص ابقى اروح اركب لولب. سيدة من محافظة بورسعيد - بr سنة ولديها طفل واحد

وقد أدى نقص بعض الوسائل في القطاع الحكومي

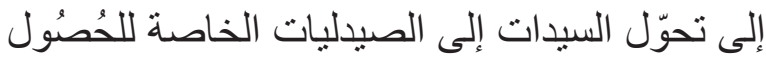

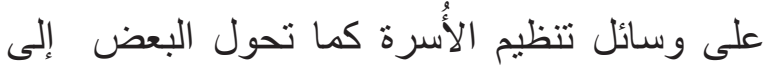

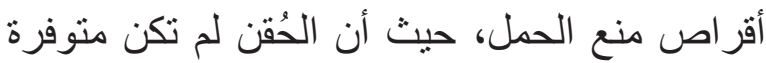

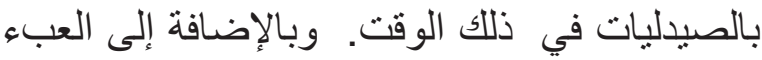

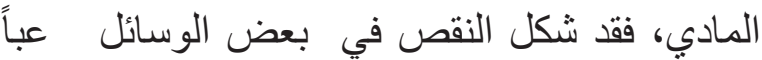

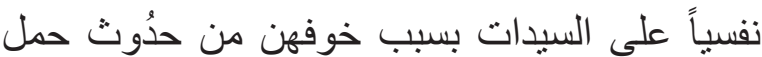
غير مُخطط له.

\section{9}

أنا كنت بروح أخد الحقن من المركز الطبي الحقنه اللي كل شهر وفي بداية موضوع الكورونا و الحظر اهن كنت بروح المركز الطبي كانوا بيقولوا انها ناقصة ولسه ماجتش فاكنت بضطر أشتربها من الصبيلية كانت لسه موجودة ومن شهربين روحت أسأل عليها

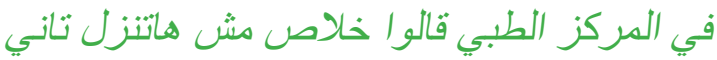
لأنها اتمنعت ودورت عليها في الصبيليات كانت مش موجودة برضو. سيدة من محافظة بورسعيد - r سنة ولديها طفلان
أنا مث بروح الوحدة الصحبة خالص عثان أجبي.

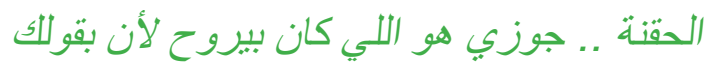

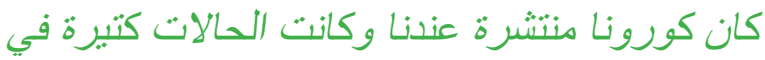

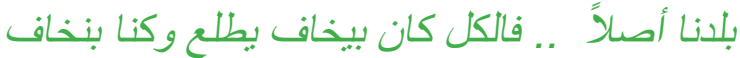

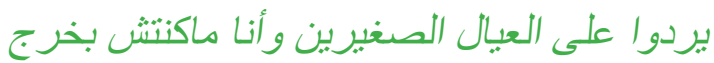
خالص من البيت عثان أنا كمان عندي حساسية البية

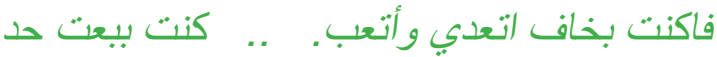
يجبيها لي واخدها في البيت .. في واحدة عندنا كانت هي اللي بتضربهالي. سيدة من ريف محافظة سوهاج- اب سنة ولايها طفلان

\section{• قص في بعض وسائل تنظيم الأسرة:}

أفاد بعض السيدات بوجود صعوبة فى الحصول على بعض الوسائل، سواء فى عيادات بودئ القطاع

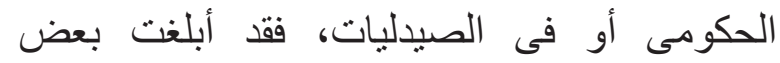

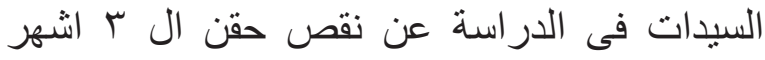
وحبوب تنظيم الأسرة في الوحدات الحكومية ونقص الحقن الثهرية في الصيدليات الخاصة، بينما أفاد الثيد بعض السيدات بتوقف بعض الأطباء بوحدات تتظيم

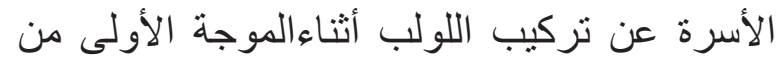
كوفيد- 9 (، خوفاً من العدوى. تركي اللولي

المشكلة أن الوحدة الصحية ماكنتش شغالة وقت الكورونا وكانو ا موقفين تنظيم الأسرة و الوسابل مدانيل

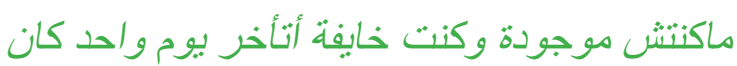
مدكن يحصل لي حمل أو مشاكل ثانبة لا قدر الله.

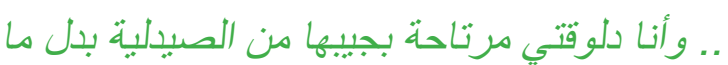

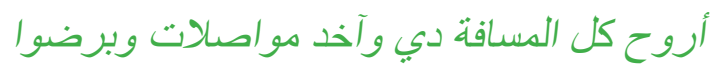
هاتكلف وممكن ملاقيش البرشام.

سيدة من ريف محافظة سوهاج - r ب عاما ولديها ثلاثة أطفال 
روحت عند دكتورة خاصة عندنا في البلد قريبة

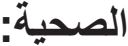
بدل ماروح بعيد واركب مو اصلات واعرض نفسى للعدوى لانى كنت متعودة اخد الوسبلة من القو افل بل الطبية اللى بتنزل عندنا في البلد وايام الكورونا مكنش فيه قو افل اضطريت اروح لدكتورة خاصنة لان جوزى رجع من السفر أبام الكورونا وكنت ل ازم اخد وسيلة.

سيدة من ريف محافظة سو هاج ـ 9 بنة ولديها طفل و احد

66

$99-$

انا لما ولدت ساعتها المستشفيات كلها كانت قافله و متحوله الى حجر صحى ومبنقلش وسن وسائل و عثان

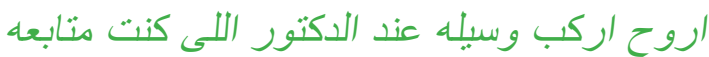

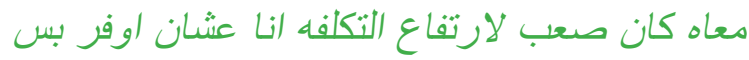

فلوس العمليه بتاعت الولاده استلفت وجوزى اخد قرض من الشغل بتاعه وكنت عامله حسابى ساعتها

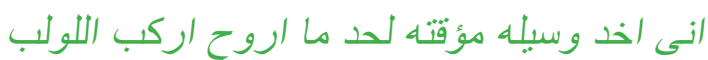

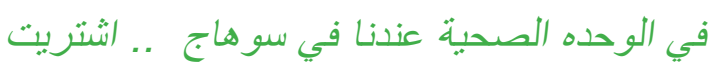
حقنة لمدة ب أشهر من الصبيلية ادتهالى أختي لأنهم رفضوا بدوهالى في الصيدلية علثان الكورونا .... وللأسف حملت عليها.

سيدة من محافظة سو هاج-- ·r سنة ولديها أربعة أطفال

\section{6}

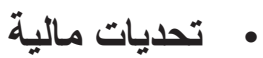

واجكت بعض السيدات صعوبات مالية نتيجة لفقد الزوج لعمله أثناء الموجة الأولى للجائحة أو بسبب اللجوء لأبهاء

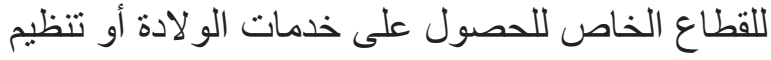

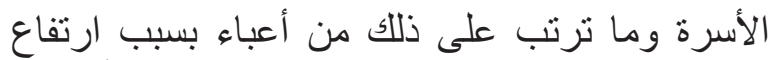

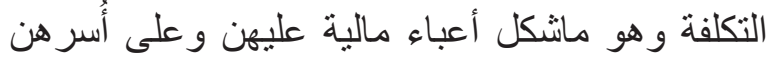

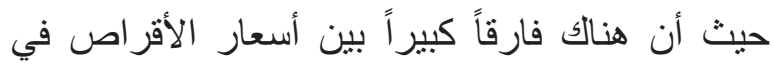

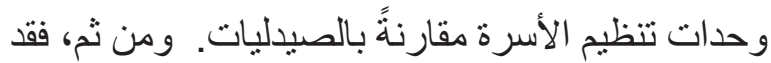

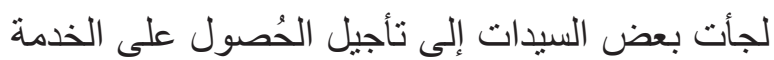
أو الحُصول عليها مباشرةً من الصيدلية بدون إسنتشارة

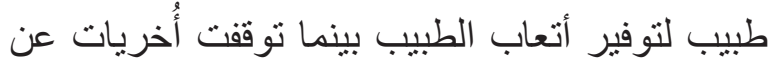
الإستخدام لتوفير ثمن الوسيلة.
ومن الصعوبات التى واجهت بعض السيدات هى الوصول إلى مقدمى خدمات تنظيم الأسرة نتيجة

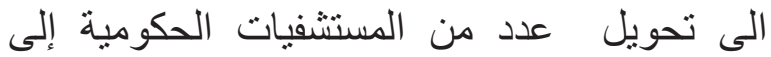
مستشفيات عزل ومن ثم غلق عيادات تتظيم الأسرة بها وكذللك غلق بعض العيادات الخاصة كما أشرنا

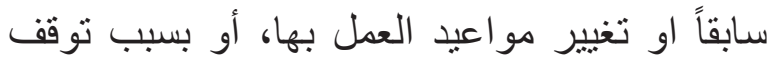
العربات المتنقلة فى بداية الجائحة.

وفى محافظة بورسعيد نتيجة الى تحويل بعض المستشفيات للعزل والبعض الاخر من المستشفيات اصبحت مخصصة لتقديم خدمات التأمين الصحى، أدى ذللك الى ضرورة حجز المستفيدات مو عد فى العيادات قبل الذهاب لتلقى الخدمة وهو ما نتج عنه فئه طول فترة الإنتظار للحصول على خدمة. وقد أدت صعوبات الوصول لمقدمي الخدمه أثناء

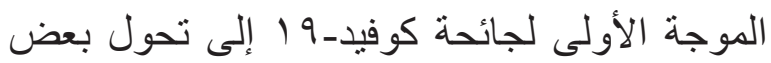
السيدات إلى خدمات القطاع الخاص الى وخاصةً الصبدليات، للحُصول على أقر اص منع الحمل بينما اضطر البعض الآخر للحصول على الخدمة مباشرةً من الصبدلية بدون إستشارة طبيب وكذلك الإستعانة بأثخاص غير مدربين كما في حالة احدى السيدات

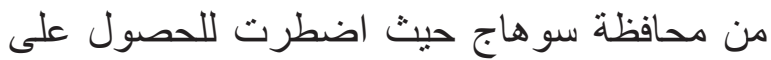

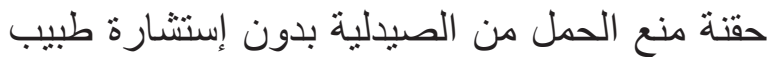

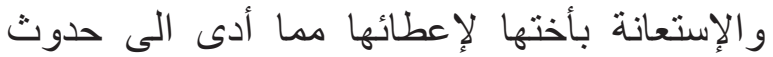
حمل غير مُخطط له.

المشكلة الوحبدة اللى قابلتنى في موضوع الوسبلة ده انى كنت متعودة اروح المركز الطبي عشان اخدا لندان

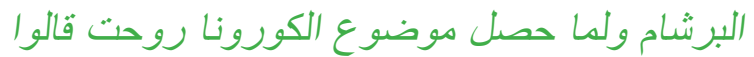

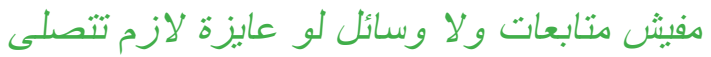

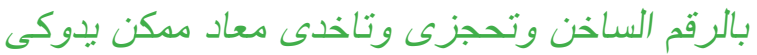
المعاد بعد شهر اواكتر. - اهن

سيدة من محافظة بور سعيد - ع سنة ولديها أربعة أطفال 
وبسبب خوف العديد من السيدات من العدوى وبسبب الإغلاق المؤقت لبعض الخدمات الحكومية وغير

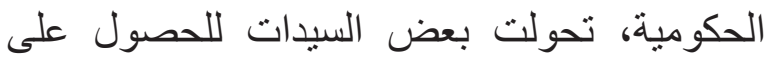

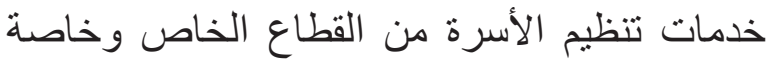
الصيدليات، مما شكل أعباء مالية عليهن وعلى ملى لاعلى

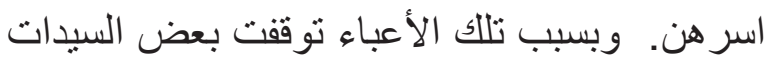

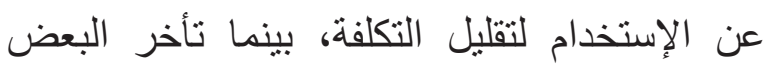

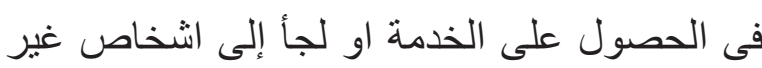
مدربين مما أدى الى حدوث حمل غير مخطط له فى بعض الاحيان.

وقد ظهر من خلال آراء الأطباء والصيادلة أن

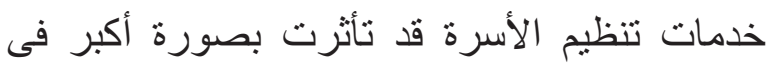

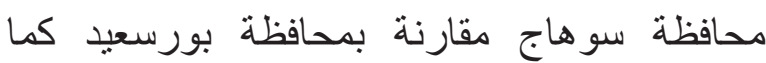
إتضح ذلك أيضـا من آراء السيدات.

ومن ناحية اخرى، إتضح أن نسبة أعلى من

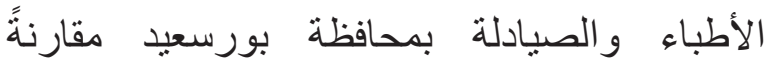
بمحافظة سوهاج يعتقدون أن تقديم خدمات تنظيم

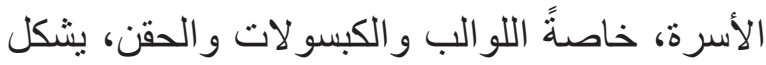
خطورة على السيدات و على مقدمي الخدمة أثناء جائحة كوفيد- 19، و ومن المرجح أن تكون تلكيد

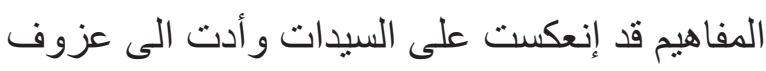

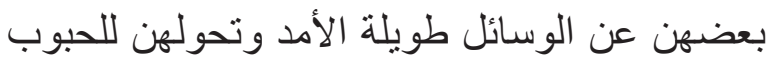
في أثناء تلك الفترة.

و الجدير بالذكر أن العينة المستخدمة فى تلك الدر اسة ليست ممثلة لمقدمى الخدمة أو السيدات على بلى الجينة مستوى الجمهورية أو محافظتي بورسعيد وسو هاج

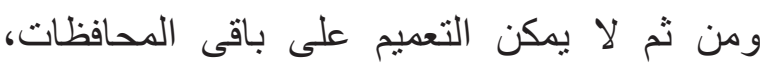

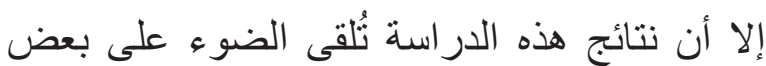
التحديات التى واجهت شريحة من السيدات وكذلك تبرز آراء ومفاهيم بعض من مقدمي الخدمة من القطاع الخاص فى تلك المحافظتين، ومن ثم، فئن فإنه

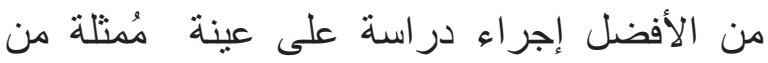
السيدات ومقدمى الخدمة من المحافظات المُختلفة للتحقق من تللك النتائج.
$99-$

أنا كنت متعوده اننا اروح لدكتور حسين واخد الوسبله

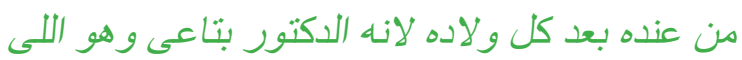

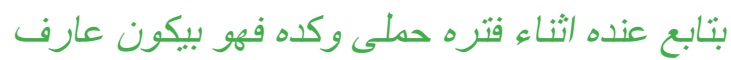
حالتى و عارف ايه الوسيله اللى هتناسبنى لكن لما جـاه موضوع كورونا ده وكده فانا ساعتها مكنتش بروح اتابع عنده قوى عشان ظروفنا الماديه كانت صعبه

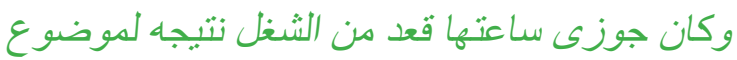
كورونا ده انا بصراحه اضطريت اننا مروحش اخدافئ

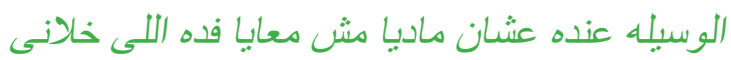

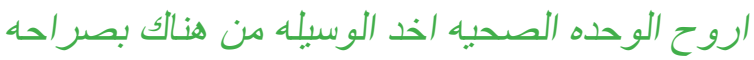

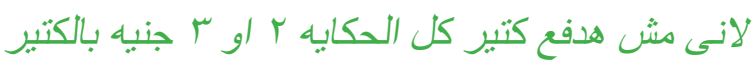
في الوحده الصحيه.

سيدة من ريف محافظة سو هاج، ب ب سنة ولديها ثلاثة اطفال

\section{6}

$99-$

جوزى جبلى الحبوب دى من الصبدلبة ب. ع جنبه . . جبتها شوبته من اول ما الكورونا بدأث كده لحد كد اخر شهر ع كده الصر احة مقدرثش استحمل انا وجوزى التكلفة دى سعر ها كان غاللى جدا علبنا وقفر. الاستخدام شوبنة بسبب موضوع التكلفة....

سيدة من محافظة بور سعبد - ـ سنة -ولايها ؛ أطفال

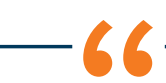

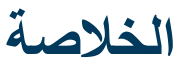

اظهرت هذه الدراسة الإستكثافية أن تفشى فيروس

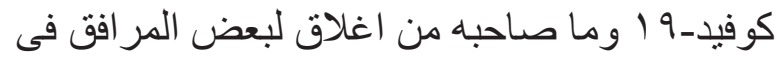

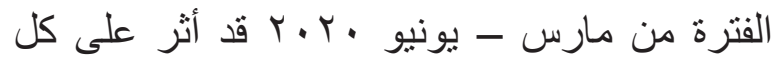
من الطلب على الخدمات وكذلك على تقديم خدمات

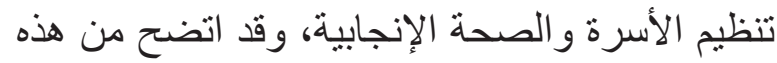

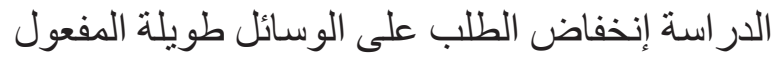

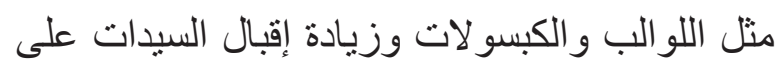
حبوب تتظيم الأسرة من الصبدليات. 
وتوزيعها على الأطباء من خلال المديريات الصحية، وكذلك من خلال صفحة الفيسبوك الك الخاصة بوز ارة الصحة و السكان.

• تكثيف المتابعة و الإشر اف من قبل وز ارة الصحة تعزيز التعاون بين وز ارة الصحة والسكان ونقابتى الأطباء و الصيادلة لتزويد الأطباء و الصيادلة فيى لئي القطاع الخاص بالمعلومات الخاصة بوسياء ولئل

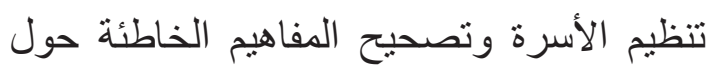
أمان و سلامة تقديم خدمات تنظيم الأسرة فى ظل وله جائجة كوفيد-9 1 ، وكذللك تعريفهم بالخط الساخن الخاص بإدارة النو اقص بوز ارة الصحة و السكان

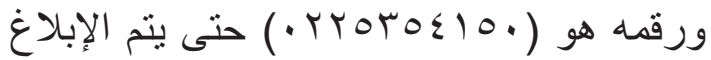
عن الوسائل التى بها نقص فى الصيدليات. وأخير ا، فقد إعتمدت هذه الدر اسة على آراء عينة من السيدات ومقدمى الخدمة بمحافظتي بورسعيد

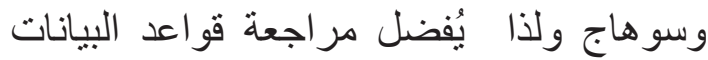
بالمديريات الصحية لتحديد ما إذا كانت نسب التردد على الخدمة ومعدلات إستخدام الوسائل المختلفة قد تأثرت بسبب جائحة كورونا.

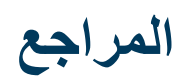

- UNFPA. 2020. «Impact of the COVID-19 Pandemic on Family Planning and Ending Gender-based Violence, Female Genital Mutilation and Child Marriage.

- UNFPA. 2021. One year into the pandemic, UNFPA estimates 12 million women have seen contraceptive interruptions leading to 1.4 million unintended pregnancies. News, 11 March 2021.

- World Health Organization. 2021. Weekly epidemiological update. https://www.who.int/publications/m/ item/weekly-epidemiological-updateon-covid-19---27-April-2021 عدم تأخر الأطباء فى تقديم وسائل تنظيم الأسرة

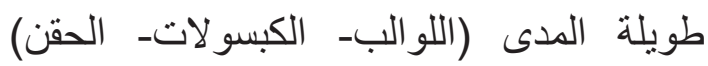
و التأكد من نطبيق إجراءات منع إنتشار العدوى

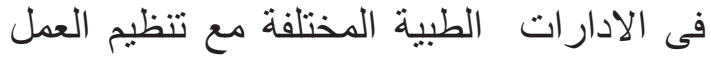
بالعيادات لتقليل الزحام و احتمالات نقل العدوى. • العمل على إستمر ار توفير عيادات تنظيم الأسرة

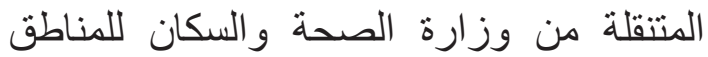

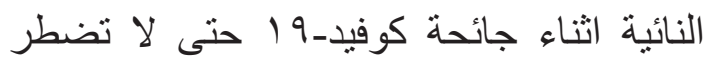

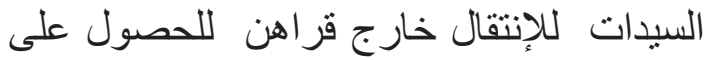
الخدمة أو التحول للقطاع الخاص ومن ثم تحمل فئل المزيد من التكلفة المادية التى قد تشكل عبئًا عليهن و على أسر هن. رفع و عى السيدات بأهمية الإستمر ار فى الحصول على خدمات تتظيم الأسرة فى فترة إنتشار الوباء،

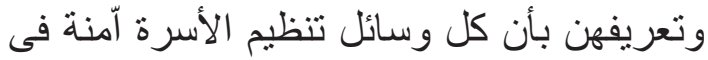

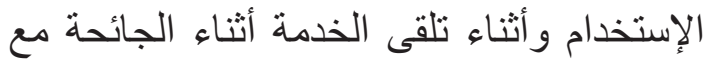
تزويدهن بالمعلومات التى تساعدهن على إتخاذ

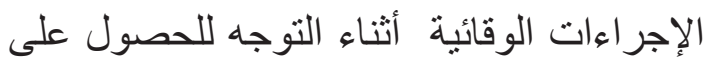
خدمات تنظيم الأسرة.

تعريف السيدات بالخط الساخن الخاص بقطاع السكان وتنظيم الأسرة بوزارة الصحة والسكان

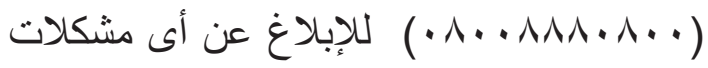
تواجههن في الحصول على الخدمة من المنافذ الحكومية.

رفع وعى الأطباء بطرق إنتشار فيروس كوفيد-9 1 وطرق الوقاية من العدوى وتصحيح المفاهيم و المعلومات الخاطئة و التاكيد على أمان و سلامة تلقى وتقديم جميع خدمات تتظيم الأسرة

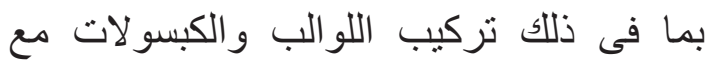
الإلتزام بالإجر اءات الوقائية اللآزمة. ويمكن فى لئ

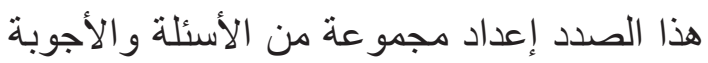
ترد على تساؤلاتهم بخصوص تقديم الخدمة 


\section{شكر وتقدير}

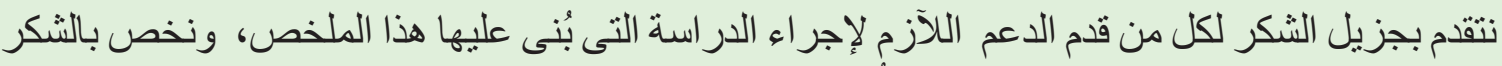

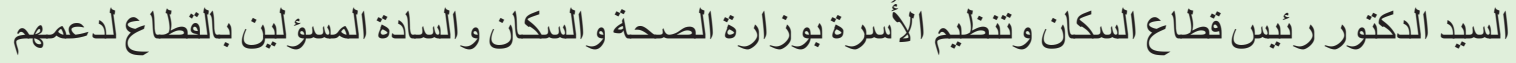

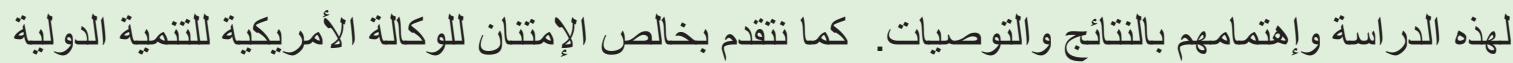

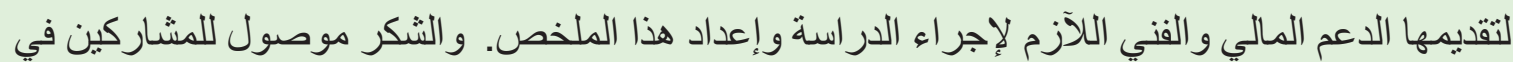

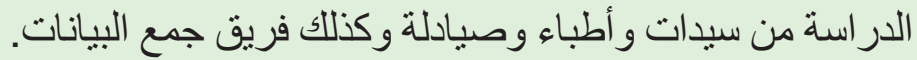

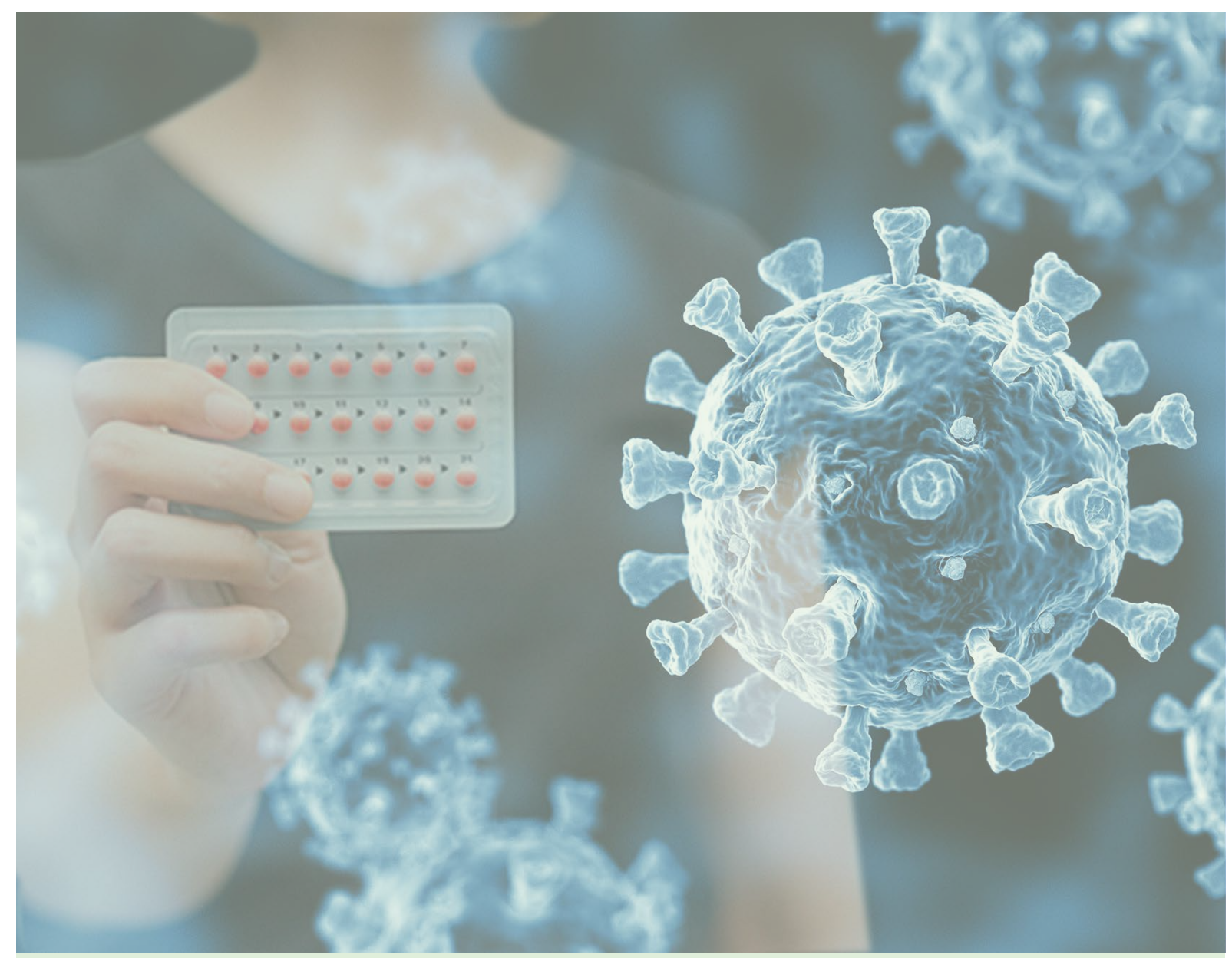




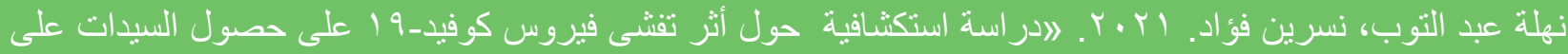

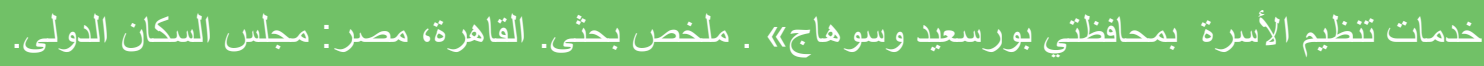

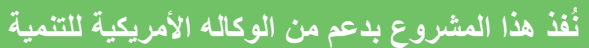

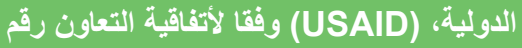
AID.OAA.A.13-00087

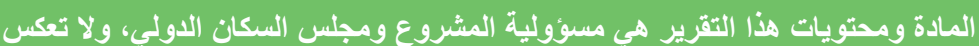

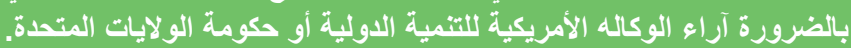

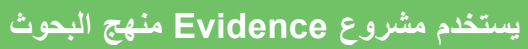

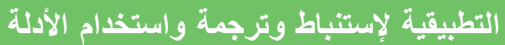

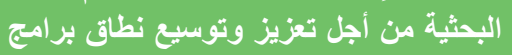

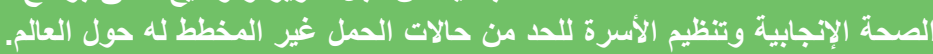

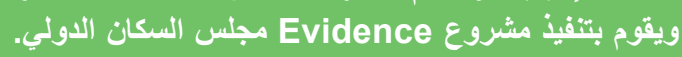

THE EVIDENCE PROJECT

$$
\begin{aligned}
& \text { مجلس السكان الدولى الثى } \\
& \text { rا شارع النهضة - المعادى الدولى } \\
& \text { صندوق بريد } 171 \text { القال }
\end{aligned}
$$

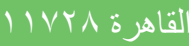

$$
\begin{aligned}
& \text { هاتف: ROAKIVY }
\end{aligned}
$$

Evidence evidenceproject@popcouncil.org

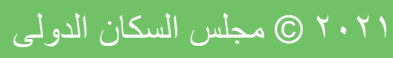

